Article

\title{
Sports Injuries in the Australian Regular Army
}

\author{
Robin Orr ${ }^{1, *(\mathbb{D}, \text { Ben Schram }}{ }^{1}\left(\mathbb{D}\right.$ and Rodney Pope ${ }^{1,2} \mathbb{C}$ \\ 1 Tactical Research Unit, Faculty of Health Science \& Medicine, Bond University, Gold Coast 4229, Australia; \\ bschram@bond.edu.au (B.S.); rpope@csu.edu.au (R.P.) \\ 2 School of Community Health, Charles Sturt University, Albury 2640, Australia \\ * Correspondence: rorr@bond.edu.au
}

Received: 13 March 2020; Accepted: 28 April 2020; Published: 11 May 2020

\begin{abstract}
Sports participation in the military is important for physical fitness and building morale and camaraderie. However, injuries caused by sports are detrimental to military capability. The purpose of this study was to investigate patterns of injury from sports participation in Australian Regular Army personnel. Injury data spanning a two-year period were obtained from the Department of Defence Workplace Health, Safety, Compensation, and Reporting (WHSCAR) database. Data were extracted for the top five sporting activities causing injuries. The most common body sites, natures, and mechanisms of injuries across these five sports were then determined. Sports participation accounted for $11 \%(n=1092)$ of reported injuries $(n=9828)$. Soccer presented with the greatest number of injuries (23.3\%), followed by rugby union/league (22.9\%), touch football (18.6\%), Australian rules football $(12.0 \%)$, and basketball/netball $(11.9 \%)$. The ankle, knee, and shoulder were the most injured body sites $(21.9 \% ; 17.2 \% ; 11.6 \%$ respectively) across these five sports, with soft tissue injury, dislocation, and fractures being the most common natures of injury $(55.1 \% ; 12.7 \% ; 11.9 \%$ respectively). The most common mechanisms of injuries were contact with objects (35.1\%) and falls (27.4\%). The current injury rates, locations, and mechanisms are similar to historical rates suggesting little impact by injury mitigation strategies.
\end{abstract}

Keywords: military; defence; sport participation; soccer; training

\section{Introduction}

Sporting participation is encouraged in defence force personnel as it is thought to have numerous benefits, including building fitness, strength, endurance, agility, teamwork, stress reduction, and "esprit de corps" [1]. The famous quote, attributed to the Duke of Wellington that "the battle of Waterloo was won on the playing fields of Eton" provides a historical military appreciation of these attributes and their potential military application [2] and was reported to have been used in the suggestion that Australia needed units similar to the sportsmen's battalions of Britain during the Great War [3]. This quote was also later touted following the cricket "Victory Test" played between Australia and Britain, which typified the sporting spirit that led these countries to defeat Germany and Japan in World War II [3].

Optimizing the benefits associated with sport and fitness while controlling risk of injury is of great importance for a defence population and presents a notable challenge [4]. Injuries in defence forces undermine capability and interfere with active duty service [5]. To reduce injuries and their downstream impacts, research in the military has typically focussed on injuries related to general military and physical training $[6,7]$. This targeted research has enabled successful intervention strategies to be implemented to reduce injury risk during these training activities [6,8-10]. However, not all injuries occur from military or physical training, and sports have been found to be a notable cause of injury in defence populations [1,11,12], to the point of impacting on operational duties [13]. Sporting injuries, 
along with injuries associated with physical training, have been reported to have the greatest cost with respect to military force readiness, lost duty time, and the monetary expenditure for treatment, rehabilitation, and compensation [1] and have been found to occur more frequently than combat-related injuries, during combat operations [4,14,15]. The Australian Defence Force Health Status Report [1], for example, found that sport $(47 \%)$ and physical training $(24 \%)$ accounted for approximately $70 \%$ of all working days lost in the Australian Defence Force from July 1997 to June 1998.

This finding of high rates of sports injuries in defence personnel is not surprising given that sport is a common cause of injuries in the civilian population and the high prevalence of such injuries is well documented in the scientific literature [16]. Risk factors contributing to such injuries can be broadly categorized as intrinsic (e.g., age, sex, overuse, lack of flexibility, muscle weakness, etc.) or extrinsic (e.g., training errors, environmental conditions, inadequate nutrition, equipment, and illegal play) in nature $[17,18]$. It is at these risk factors that most risk minimization plans are specifically targeted (e.g., specific programs targeting deficits in range of motion or muscle imbalances, or prophylactic taping and bracing) [19].

With previous research $[6,9,10,20]$ supporting the use of targeted interventions for risk minimization, effective and informed injury prevention strategies for sports could provide a good return on investment for military forces, with respect to readiness and productivity as well as decreased financial burden [1]. However, in order to address the injury rates associated with sporting participation in defence forces through implementation of effective injury prevention programs, commanders require a detailed sporting injury profile that identifies sites, natures, and causes of injuries [14]. The aim of this study was to identify the major sports leading to injury in the Australian Regular Army and to investigate body sites, injury types, and mechanisms associated with these injuries, to inform future risk reduction strategies.

\section{Materials and Methods}

Retrospective work health and safety incident and injury data were sourced from the Workplace Health, Safety, Compensation, and Reporting (WHSCAR) database of the Australian Department of Defence, which constitutes the source of records of incidents and injuries sustained by army personnel. The WHSCAR database is designed to capture all incident reports submitted in the notification and reporting of Workplace Health and Safety incidents occurring within the Department of Defence [21]. In reality, it has been estimated to capture only $11 \%-19 \%$ of all injury incidents that require health care [22], though it is likely to capture a much higher proportion of serious injuries, which result in longer-term disability or compensation, since reporting of such incidents is an essential step in demonstrating eligibility for compensation. The WHSCAR database nevertheless provides a useful overview of the "patterns" of injuries experienced by Australian Defence Force personnel, particularly given it is the only available source of such data, but caution should be applied in interpretation of the "rates" of injuries calculated from this database [22]. A qualified WHSCAR database operator extracted the data from the database in order to ensure optimal data retrieval and redacted all personal information to ensure that the data was non-identifiable. The WHSCAR data provided to the researchers spanned the period 01 July 2012 to 30 June 2014 and included military service (i.e., army) and the service type (part-time or full-time) to which the affected person belonged, type of occurrence, date of incident, incident severity, nature of resulting injury, body site affected by resulting injury, mechanism of resulting injury, activity at the time of the incident (including specific event, i.e., actual sport being played), incident description, and duty status at the time of the incident.

Work health and safety incident and injury records extracted from the WHSCAR database were included in the analysis if they related to: (a) full-time service; (b) a minor or serious personnel injury that occurred while the person was "on duty"; (c) an injury that occurred during sports participation in an Australian Defence Force-recognized sport [23]; and (d) an injury that occurred between 1 July 2012 and 30 June 2014, inclusive. Data from part-time personnel were removed, as previous published research in this population [24] found a 71\% lower incidence of sporting injuries in part-time versus 
full-time personnel; given the low rate of injuries and the noted differences between part-time and full-time personnel [24], inclusion of part-time personnel had the potential to introduce multiple confounding factors. The intent of including only "on duty" injuries was to allow comparison to previous research in this area. It should be noted that personnel authorized to play a given army-approved sport would be classified as "on duty" even if the injury occurred outside traditional working hours. The definitions of injury, be it a minor personal injury (MPI) or serious personal injury (SPI), were those derived, and defined, by the Australian Department of Defence [21], whereby an MPI is generally defined as a minor injury that did not result in a fatality, SPI, or a dangerous occurrence; and an SPI is generally defined as an injury requiring immediate treatment as an in-patient in hospital or for other series injuries (e.g., to the head, eye, amputation, etc). Records were excluded if they: (a) related to personnel from a foreign defence service, on secondment; or (b) contained missing or incomplete data.

The Australian Defence Human Research Ethics Committee (ADHREC, LERP14-024) and the Bond University Human Research Ethics Committee (BUHREC, RO-1907) granted ethics approval for this study. Departmental authorization for the project was obtained in parallel to the process for obtaining ADHREC approval.

\section{Data Analysis}

The WHSCAR data were provided in a Microsoft Excel spread sheet and were manually cleaned to ensure that only the records consistent with the inclusion and exclusion criteria were retained. In addition, each line of data was reviewed and compared to other lines of data to ensure identification and removal of duplicate entries (i.e., same record entered twice). Each data record was further verified, corrected, or made more precise by manually comparing the allocated "Type of Occurrence Classification System" (TOOCS) classifications with the free-text narrative data from the same record. When discrepancies were identified, precedence was given to the free-text narratives and the TOOCS classification was adjusted accordingly. Narratives provided by incident reporters are considered more detailed and accurate than data entered by a third party using a finite coding system [25]. The resulting, often more precise, TOOCS codes were employed in the subsequent data analysis. To increase data accuracy, brevity, and sensitivity, the TOOCS fields for "nature of injury" were aggregated, whereby "soft tissue injuries due to trauma or unknown mechanism" included "trauma to muscle" (a soft tissue) and "trauma to tendons" (a soft tissue) and for brevity was re-termed as "soft tissue injuries due to trauma". In addition, "trauma to joints and ligaments, not elsewhere classified" and "trauma to joints and ligaments unspecified" were merged into "trauma to joints and ligaments".

Descriptive analyses were employed to identify the most common sports in which injuries occurred. Subsequent analyses then focussed on the top five sports in which injuries occurred, and the most prevalent anatomical locations, natures, and mechanism of these injuries were then determined.

\section{Results}

A total of 9828 injuries were reported amongst Australian Regular Army personnel over the data collection period. In total, MPI accounted for $93.21 \%(n=9161)$ of these injuries, with the remaining $6.79 \%(n=667)$ of reported injuries being classified as SPI. Sports participation was the third highest cause of reported injuries in army personnel $(\mathrm{n}=1092,11.11 \%)$, only preceded by physical training $(\mathrm{n}=3230,32.87 \%)$ and combat training $(\mathrm{n}=1747,17.80 \%)$. When the sports data were reviewed specifically, no duplicates or incomplete datasets were found. However, 15 cells contained data in the TOOCS code that differed from those in the free-text narratives and the TOOCS classification was adjusted accordingly. For example, although initially entered as a "foot" injury, the free-text descriptor in one case specifically detailed a lateral ankle sprain. As such, the TOOCS classification was changed to "ankle".

The highest numbers of injuries were observed in soccer, with 254 reported MPI and SPI (Table 1), slightly higher than in "rugby union or league" $(n=250,22.89 \%)$ and touch-football $(n=203,18.59 \%)$. 
Other sports associated with a high number of injuries included Australian rules football $(\mathrm{n}=131$, $12.00 \%)$ and basketball or netball $(n=130,11.90 \%)$. A higher number of SPIs were reported in rugby union or league than in any other sport $(n=22,27.50 \%)$.

Table 1. Australian Regular Army reported injuries associated with sport participation.

\begin{tabular}{ccccccc}
\hline Sport & \multicolumn{2}{c}{ MPI n (\%) } & \multicolumn{2}{c}{ SPI n (\%) } & \multicolumn{2}{c}{ MPI and SPI n (\%) } \\
\hline Soccer & 238 & $(23.52)$ & 16 & $(20.00)$ & 254 & $(23.26)$ \\
Rugby union/league & 228 & $(22.53)$ & 22 & $(27.50)$ & 250 & $(22.89)$ \\
Touch football & 189 & $(18.68)$ & 14 & $(17.50)$ & 203 & $(18.59)$ \\
Australian rules & 120 & $(11.86)$ & 11 & $(13.75)$ & 131 & $(12.00)$ \\
Basketball/netball & 125 & $(12.35)$ & 5 & $(6.25)$ & 130 & $(11.90)$ \\
Total of top 5 & 900 & $(88.93)$ & 68 & $(85.00)$ & 968 & $(88.65)$ \\
\hline Total of all injuries & 1012 & $(100.00)$ & 80 & $(100.00)$ & 1092 & $(100.00)$ \\
\hline
\end{tabular}

MPI = minor personal injury (an injury that did not result in a fatality or SPI); SPI = serious personal injury (an injury requiring immediate treatment as an in-patient in hospital or for other series injuries).

The ankle was the most commonly injured body site in these five sports, accounting for $21.90 \%$ of all reported injuries $(n=212)$, and was followed by the knee $(n=166$ injuries, $17.15 \%)$ and the shoulder $(n=112,11.57 \%)$ (Table 2$)$. The knee and head recorded the highest numbers of SPI $(n=13$ SPIs each, $19.12 \%$ ) in these sports, followed by the shoulder ( $n=11,16.18 \%)$. The majority of SPIs at the knee were due to dislocation (30.77\%), meniscal injuries $(23.08 \%)$, or ligamentous injuries $(23.08 \%)$. The majority of SPIs to the head were due to concussion (46.16\%). Within soccer, the ankle (76 MPIs and $1 \mathrm{SPI}$ ), knee (37 MPIs and 5 SPIs), and upper leg (17 MPIs) were the most common sites of injury, while the most common sites of injury in rugby union league were the shoulder (49 MPIs and 5 SPIs), the knee (32 MPIs and 5 SPIs), and the ankle (30 MPIs and 2 SPIs). The ankle (40 MPIs and 3 SPIs), knee (34 MPIs and 2 SPIs), and shoulder (18 MPIs and 2 SPIs) were also the most commonly injured in touch football.

Table 2. Reported location of injuries amongst Australian Regular Army personnel in the top five injuring sports.

\begin{tabular}{ccccccc}
\hline Location & \multicolumn{2}{c}{ MPI $\mathbf{n}(\mathbf{\%})$} & \multicolumn{2}{c}{ SPI n (\%) } & \multicolumn{2}{c}{ MPI and SPI n (\%) } \\
\hline Ankle & 205 & $(22.78)$ & 7 & $(10.29)$ & 212 & $(21.90)$ \\
Knee & 153 & $(17.00)$ & 13 & $(19.12)$ & 166 & $(17.15)$ \\
Shoulder & 101 & $(11.22)$ & 11 & $(16.18)$ & 112 & $(11.57)$ \\
Hand & 73 & $(8.11)$ & 3 & $(4.41)$ & 76 & $(7.85)$ \\
Head & 50 & $(5.56)$ & 13 & $(19.12)$ & 63 & $(6.51)$ \\
Thigh & 49 & $(5.44)$ & 0 & $(0.00)$ & 49 & $(5.06)$ \\
Foot & 39 & $(4.33)$ & 3 & $(4.41)$ & 42 & $(4.34)$ \\
Back & 38 & $(4.22)$ & 1 & $(1.47)$ & 39 & $(4.03)$ \\
Wrist & 26 & $(2.89)$ & 3 & $(4.41)$ & 29 & $(3.00)$ \\
Lower limb & 22 & $(2.44)$ & 2 & $(2.94)$ & 24 & $(2.48)$ \\
Upper torso & 18 & $(2.00)$ & 2 & $(2.94)$ & 20 & $(2.07)$ \\
Gastroc-soleus complex & 16 & $(1.78)$ & 1 & $(1.47)$ & 17 & $(1.76)$ \\
Multiple & 15 & $(1.67)$ & 2 & $(2.94)$ & 17 & $(1.76)$ \\
Upper limb & 14 & $(1.56)$ & 3 & $(4.41)$ & 17 & $(1.76)$ \\
Abdomen & 15 & $(1.67)$ & 0 & $(0.00)$ & 15 & $(1.55)$ \\
Lower limb multiple & 14 & $(1.56)$ & 1 & $(1.47)$ & 15 & $(1.55)$ \\
Neck & 15 & $(1.67)$ & 0 & $(0.00)$ & 15 & $(1.55)$ \\
Organs & 10 & $(1.11)$ & 1 & $(1.47)$ & 11 & $(1.14)$ \\
Shins & 9 & $(1.00)$ & 0 & $(0.00)$ & 9 & $(0.93)$ \\
Hip & 7 & $(0.78)$ & 1 & $(1.47)$ & 8 & $(0.83)$ \\
Elbow & 5 & $(0.56)$ & 0 & $(0.00)$ & 5 & $(0.52)$ \\
Neck and shoulder & 4 & $(0.44)$ & 0 & $(0.00)$ & 4 & $(0.41)$ \\
Pelvis & 1 & $(0.11)$ & 1 & $(1.47)$ & 2 & $(0.21)$ \\
Systemic & 1 & $(0.11)$ & 0 & $(0.00)$ & 1 & $(0.10)$ \\
\hline Total & 900 & $(100)$ & 68 & $(100)$ & 968 & $(100)$ \\
\hline
\end{tabular}

MPI = minor personal injury (an injury that did not result in a fatality or SPI); SPI = serious personal injury (an injury requiring immediate treatment as an in-patient in hospital or for other series injuries). 
The most common nature of injury in these five sports was soft tissue injuries due to trauma, accounting for $55.06 \%$ of all injuries $(n=533)$ and 11 SPIs (Table 3$)$. Dislocations $(n=123,12.71 \%)$ and other fractures ( $\mathrm{n}=115,11.88 \%$ ) were reported frequently, with both accounting for high numbers of SPIs ( $n=13$ and $n=25$, respectively). Dislocations were predominately at the shoulder $(n=47,38.21 \%)$ and knee $(n=37,30.08 \%)$. Other fractures were the most commonly reported SPI $(n=25,36.76 \%)$. The main site of fracture was at the hand, inclusive of fingers $(n=29,25.21 \%$ of all fractures in these five sports). These patterns of incidence for nature of injury were reflected across three leading sports. For soccer, soft tissue injuries (123 MPIs and 1 SPI), fractures (16 MPIs and 6 SPIs), and dislocations (12 MPIs and 3 SPIs) were the most common. In both rugby league/union and touch football, soft tissue injuries (75 MPIs and 2 SPIs and 96 MPIs and 2 SPIs, respectively) were the most common, followed by dislocations ( 40 MPIs, 5 SPIs and 23 MPIs, 4 SPIs, respectively) and fractures (32 MPIs, 7 SPIs and 20 MPIs, 5 SPIs, respectively).

Table 3. The top five reported natures of injury in sports played by Australian Regular Army personnel.

\begin{tabular}{ccccccc}
\hline Nature of Injury & \multicolumn{2}{c}{ MPI $\mathbf{n}(\%)$} & \multicolumn{2}{c}{ SPI n (\%) } & \multicolumn{2}{c}{ MPI and SPI n (\%) } \\
\hline Soft tissue injuries due to trauma or & 522 & $(58.00)$ & 11 & $(16.18)$ & 533 & $(55.06)$ \\
unknown mechanisms & 110 & $(12.22)$ & 13 & $(19.12)$ & 123 & $(12.71)$ \\
Dislocation & 90 & $(10.00)$ & 25 & $(36.76)$ & 115 & $(11.88)$ \\
Other fractures & 60 & $(6.67)$ & 4 & $(5.88)$ & 64 & $(6.61)$ \\
Trauma to joints and ligaments & 22 & $(2.44)$ & 8 & $(11.76)$ & 30 & $(3.10)$ \\
Other intracranial injury & 804 & $(89.33)$ & 61 & $(89.70)$ & 865 & $(89.36)$ \\
\hline Total of top 5 injuring sports & 900 & $(100)$ & 68 & $(100)$ & 968 & $(100)$ \\
\hline Total of all sports injuries & &
\end{tabular}

MPI = minor personal injury (an injury that did not result in a fatality or SPI); SPI = serious personal injury (an injury requiring immediate treatment as an in-patient in hospital or for other series injuries).

The most common mechanisms for injuries amongst army personnel in these five sports are detailed in Table 4. Contact with moving or stationary objects was the most prevalent mechanism, accounting for the highest number of both MPI $(n=300)$ and SPI $(n=40)$. This mechanism, along with falls $(n=250,27.78 \%)$ and muscular stress with no objects being handled $(n=246,27.33 \%)$, comprised $88.33 \%$ of all injuries in these five sports. In soccer, muscular stress (81 MPIs and $1 \mathrm{SPI}$ ), contact with a moving or stationary object (67 MPIs and 8 SPIs), and falls (66 MPIs and 5 SPIs) were the most common mechanisms of injury. In rugby league/union contact with a moving or stationary object (104 MPIs and 16 SPIs), muscular stress (42 MPIs and 1 SPI), and falls (38 MPIs and 1 SPI) and in touch football with falls (71 MPIs and 3 SPIs), muscular stress (57 MPIs), and contact with moving or stationary objects (40 MPIs and 8 SPIs).

Table 4. The reported mechanism of sporting-related injuries in Australian Regular Army personnel.

\begin{tabular}{ccccccc}
\hline Mechanism of Injury & \multicolumn{2}{c}{ MPI $\mathbf{n}(\%)$} & \multicolumn{2}{c}{ SPI n (\%) } & \multicolumn{2}{c}{ MPI and SPI n (\%) } \\
\hline Contact with moving or stationary object & 300 & $(33.33)$ & 40 & $(58.82)$ & 340 & $(35.12)$ \\
\hline Falls & 250 & $(27.78)$ & 15 & $(22.06)$ & 265 & $(27.38)$ \\
\hline Muscular stress with no objects being handled & 246 & $(27.33)$ & 4 & $(5.88)$ & 250 & $(25.83)$ \\
\hline Being hit by a person accidentally & 65 & $(7.22)$ & 5 & $(7.35)$ & 70 & $(7.23)$ \\
\hline Muscular stress while lifting carrying or putting & 13 & $(1.44)$ & 0 & $(0.00)$ & 13 & $(1.34)$ \\
\hline Total of top 5 injuring sports & 874 & $(97.11)$ & 64 & $(94.11)$ & 938 & $(96.90)$ \\
\hline Total of all mechanisms & 900 & $(100)$ & 68 & $(100)$ & 968 & $(100)$ \\
\hline
\end{tabular}

MPI = minor personal injury (an injury that did not result in a fatality or SPI); SPI = serious personal injury (an injury requiring immediate treatment as an in-patient in hospital or for other series injuries). 


\section{Discussion}

This study aimed to investigate sporting injuries amongst Australian Regular Army personnel, specifically highlighting the site, nature, and mechanism most commonly associated with injury in sports. In this study of the Australian Regular Army, sports were the third most common activity to cause injury and accounted for $11 \%$ of all injuries in the army. Playing sport was also the second most common cause of SPI, associated with 80 SPIs over a two-year period. This finding is similar to findings from the previous Australian Defence Force (ADF) Health Status Report [1] in which $13.9 \%$ of ADF injuries could be attributed to sport.

In the top five sports associated with causing injury in this study, the ankle was the most commonly injured body site, featuring a high number of minor injuries but fewer serious injuries than the knee, which was the second most commonly injured body site. Injuries at or below the knee are traditionally the most commonly reported site of injury in military populations $[6,7,26]$, with both the ankle and knee featuring heavily in the ADF health status report in 2000 [1]. In a review of civilian sports from the Australian population and in line with this research, the ankle was the leading site of injury followed by the knee in soccer ( $21 \%$ and $16.3 \%$, respectively) [27]. The ankle and knee were also a leading site of injury in basketball (16\% and $11 \%$, respectively) and netball ( $40 \%$ and $18 \%$, respectively) [27]. In Australian rules football the knee and the ankle were the second and third most commonly injured sites (knee 12\% and $8 \%$ respectively) with the thigh being the leading site (20\%) [27]. Similarly, the ankle was the leading site of injury in touch football (23\%) concurring with the results of this study, followed by the leg (16\%) and the knee (15\%) [27]. Given that these aforementioned sports were leading sports found to cause injury in this army population, the findings of high ankle and knee injury rates was not unexpected. Considering this, understanding the risk factors associated with injuries to these body sites in the civilian community could help guide future risk management strategies in military personnel.

Despite some proportion of the risk of injury being attributable to poor conditioning [19], the leading risk factor for ankle injuries is a history of ankle injury [28]. Ligaments particularly have a reduced tensile strength (50\%-70\% that of uninjured tissue) [29] and decreased mechanoreceptor function following injury, leading to poor joint position sense post injury [30]. Likewise, previous knee injuries have been associated with subsequent knee injuries amongst military personnel [31]. Participation in sport is itself a risk factor for knee injury [32], along with poor quadriceps function, which is a common sequela post knee injury [33]. High-impact activity both from combat training and drills and carrying heavy loads may also increase stress on the knee joint in this population [34]. On this basis, the reconditioning program for the injured site needs to consider the overall training load that the soldier is subject to [35], noting that some of these loads will come from the soldier's general military training and work requirements [36].

Soft tissue injuries were by far the most common nature of sporting injuries in this study, accounting for more than half of the reported injuries. Soft tissue injuries around the ankle were most commonly sprains, while soft tissues at the knee primarily consist of damage to the meniscus and ligaments [37]. Dislocations and fractures, which were the second and third most common nature of sporting injuries in this study, account for almost a quarter of all sporting injuries. Dislocations at the shoulder, especially, may have a more significant impact despite being less in number than soft tissue injuries, as previous research has demonstrated that over a quarter of shoulder dislocations lead to be chronic or recurrent injuries [38]. Furthermore, given the high rate of associated issues such as Bankart or Hills Sachs lesions with traumatic shoulder dislocations, many require surgical intervention and subsequently a long recovery period [39]. The ADF Health Status Report [1] stated that sprains and strains were the most prevalent type of injury at that time, accounting for almost $30 \%$ of all reported injuries, a figure notably lower than the $50 \%$ observed in this current study. The reasons for these differences in prevalence are not known.

"Contact with objects" was the leading mechanism of sporting injuries in this study. With approximately $50 \%$ of soccer based injuries (the leading sport associated with injury in this study 
and the second most common mechanism of injury) due to player-to-player contact [40], this mechanism of injury being a leading mechanism is not surprising. It should be noted that it has been suggested that up to $35 \%$ of soccer contact injuries can be attributed to unfair play potentiating player-to-player contact [41]. The combined mechanisms of injury-causing falls and muscular stress accounted for over $50 \%$ of the sporting injuries in this study. Falls have previously been linked to $33 \%$ of all touch football injuries (the leading mechanism of touch football injuries in this study), $19 \%$ of soccer injuries, and $11 \%$ of rugby union/league injuries (the third most common mechanism of injury in those sports in this study) [1]. Ground surfaces have been found to be responsible for many falls associated with sporting injuries, while muscular stress is often due to both training errors and over training [1]. The finding in this study is supported by research in a U.S. defence population, which found that overly aggressive play and poorly maintained surfaces were the leading contributors to sports and recreation based injuries [42]. On this basis, ensuring that injury reporting processes include a description of the playing surface may be of value. This information could be used to identify surfaces that may increase injury risk and subsequently guide the appropriate choice of surface to play sports at different geographical locations.

High-risk sports identified in this study included soccer, rugby (rugby union or rugby league), touch football, Australian rules football, and basketball or netball. These sports were responsible for $88.64 \%$ of reported sporting injuries and are therefore where preventative measures should be primarily focussed. These same sports feature heavily in the ADF Health Status Report [1], which recommended that qualified supervision, world class techniques, and education of commanders and personnel on risk minimization strategies, be put in place. Highlighted in the report, $30 \%-50 \%$ of sports injuries were claimed to be preventable, varying across different sports. It is thought that over half of the injuries associated with sport are due to human error, $31 \%$ are due to environment, and $15 \%$ due to equipment [1]. Furthermore, the report postulated that up to $20 \%$ of injuries could be prevented by education and $17 \%$ by modifying the environment [1].

Following on from the ADF Health Status Report [1], a report by Sherrard et al. [19] made specific recommendations to reduce injuries in the ADF. These recommendations notably focussed on soccer, rugby, and touch football (the three sports with the highest number of associated sporting injuries) as well as the ankle, knee, and shoulder (the three bodily sites with the highest number of associated sporting injuries). Recommendations ranged from approaches to mitigate injuries due to foul play, through to improved refereeing, and awareness-raising programs to encourage a culture of fair play and safe participation, and the use of prophylactic taping and bracing and addressing imbalances and flexibility deficits to minimize overuse injuries [19]. In addition, there has been a plethora of investigations of sporting injuries in the civilian sporting context that focus either on the sports themselves (e.g., soccer injuries [17,40,43]) or on the sites of injuries (e.g., ankle [44,45]) providing further insight and guidance for targeted intervention strategies.

Despite these recommendations, and while many intervention programs have had success in preventing combat training [9] and physical training $[6,10,20]$ injuries, it appears that reducing injuries suffered by personnel playing sports is still a challenge. Given that a range of recommendations exist, in both military and civilian sporting contexts, future research should focus on investigating whether these recommendations are appropriate to this unique population and whether these recommendations are, or can be, effectively employed in the military sporting population.

\section{Limitations}

The leading sports identified to be causing injuries in this study are clearly influenced by cultural factors specific to the country in which this study was undertaken (being the Australia Army). The high incidence of injuries in Australian rules football, a sport rarely played in other countries, serves as an example. In the United Sates Army, more injuries are seen in basketball, American football, and softball [11], while in the British Army, soccer injuries are more prevalent [13]. As such, cultural differences may need to be considered before implementing or adopting sports injury prevention 
strategies in or from other defence forces. Apart from potential underreporting of minor injuries [22], it is acknowledged that sporting injuries may have occurred during other activities (for example an injury that may have occurred during a game of touch football that was played at the end of a physical training session may be recorded as a physical training injury rather than as a sporting injury), and as such, the actual number of injuries is anticipated to be a very conservative reflection. Finally, the data did not contain information regarding the gender of the person injured, the numbers of players, or levels of exposure (i.e., cumulative number of hours played) for the individual sports. One potential means of improving the quality of this data may be through the employment of point-of-care reporting systems [22] (as opposed to the current self-reporting).

\section{Conclusions}

Sports participation is still a leading cause of injuries in army personnel with soccer and rugby being the leading sports associated with these injuries. The ankle, knee, and shoulder are the joints most injured through soft tissue trauma, dislocation, and fracture. It is hoped that the results of this study will inform and guide future injury prevention and management strategies not only for the Australian Army, but also for other military services, which suffer from a high number of sporting related injuries. It is proposed that by ensuring ground surfaces are adequate for sport, good refereeing practices are introduced and enforced to minimize foul play, and ensuring that injuries are rehabilitated properly, it might be possible to reduce injuries in the sports highlighted in this study.

Author Contributions: Conceptualization, R.O., B.S., and R.P.; methodology, R.O., B.S., and R.P.; software, R.O. and B.S.; validation, R.O. and B.S.; formal analysis, R.O., B.S., and R.P.; investigation, R.O., B.S., and R.P.; resources, R.O., B.S., and R.P.; data curation, R.O. and B.S.; writing-original draft preparation, R.O., B.S., and R.P.; writing-review and editing, R.O., B.S., and R.P.; visualization, R.O., B.S., and R.P.; supervision, R.O. and R.P.; project administration, R.O., B.S., and R.P.; funding acquisition, R.O. and B.S. All authors have read and agreed to the published version of the manuscript.

Funding: This research was partially supported by a Defence Health Foundation Grant.

Conflicts of Interest: The authors have no conflict of interest to declare.

\section{References}

1. Defence, D.O. Australian Defence Force Health Status Report; Australian Government Department of Defence: Canberra, Australia, 2000.

2. Knowles, E. (Ed.) The Oxford Dictionary of Phrase, Saying, and Quotation; Oxford University Press: Oxford, UK, 1997.

3. Blackburn, K. War, Sport and the Anzac Tradition; Springer: Berlin/Heidelberg, Germany, 2016.

4. Hauret, K.G.; Bedno, S.; Loringer, K.; Kao, T.-C.; Mallon, T.; Jones, B.H. Epidemiology of Exerciseand Sports-Related Injuries in a Population of Young, Physically Active Adults: A Survey of Military Servicemembers. Am. J. Sports Med. 2015, 43, 2645. [CrossRef] [PubMed]

5. Defence, D.O. Defence White Paper; Australian Government Department of Defence: Canberra, Australia, 2016.

6. Kaufman, K.R.; Brodine, S.; Shaffer, R. Military training-related injuries: Surveillance, research, and prevention. Am. J. Prev. Med. 2000, 18, 54-63. [CrossRef]

7. Knapik, J.J.; Sharp, M.A.; Canham-Chervak, M.; Hauret, K.; Patton, J.F.; Jones, B.H. Risk factors for training-related injuries among men and women in basic combat training. Med. Sci. Sports Exerc. 2001, 33, 946. [CrossRef] [PubMed]

8. Pope, R.P. Injury surveillance and systematic investigation identify a rubber matting hazard for anterior cruciate ligament rupture on an obstacle course. Mil. Med. 2002, 167, 359-362. [CrossRef] [PubMed]

9. Amoroso, P.J.; Ryan, J.B.; Bickley, B.; Leitschuh, P.; Taylor, D.C.; Jones, B.H. Braced for impact: Reducing military paratroopers' ankle sprains using outside-the-boot braces. J. Trauma 1998, 45, 575-580. [CrossRef]

10. Almeida, S.A.; Maxwell Williams, K.; Shaffer, R.A.; Luz, J.T.; Badong, K.E.; Brodine, S.K. A physical Training Program to Reduce Musculoskeletal Injuries in U.S. Marine Corps Recruits; Technical Report; Naval Health Research Center, National Technical Information Service, U.S. Department of Commerce: Washington, DC, USA, 1997. 
11. Lauder, T.D.; Baker, S.P.; Smith, G.S.; Lincoln, A.E. Sports and physical training injury hospitalizations in the army. Am. J. Prev. Med. 2000, 18, 118-128. [CrossRef]

12. Strowbridge, N.; Burgess, K. Sports and training injuries in British soldiers: The Colchester Garrison Sports Injury and Rehabilitation Centre. J. R. Army Med. Corps 2002, 148, 236-243. [CrossRef]

13. Adams, M.; Croft, A. Sports injuries in British troops deployed on Operation Resolute (Bosnia). J. R. Army Med Corps 1997, 143, 35-38. [CrossRef]

14. Jones, B.H.; Canham-Chervak, M.; Canada, S.; Mitchener, T.A.; Moore, S. Medical Surveillance of Injuries in the U.S. Military: Descriptive Epidemiology and Recommendations for Improvement. Am. J. Prev. Med. 2010, 38, S42-S60. [CrossRef]

15. Hauret, K.G.; Taylor, B.J.; Clemmons, N.S.; Block, S.R.; Jones, B.H. Frequency and Causes of Nonbattle Injuries Air Evacuated from Operations Iraqi Freedom and Enduring Freedom, U.S. Army, 2001-2006. Am. J. Prev. Med. 2010, 38, S94-S107. [CrossRef]

16. Mueller-Wohlfahrt, H.-W.; Haensel, L.; Ekstrand, J.; English, B.; McNally, S.; Orchard, J.; van Dijk, C.N.; Kerkhoffs, G.M.; Schamasch, P.; Blottner, D.; et al. Terminology and Classification of Muscle Injuries in Sport: The Munich Consensus Statement. Br. J. Sports Med. 2013. [CrossRef] [PubMed]

17. Junge, A.; Dvorak, J. Soccer Injuries. Sports Med. 2004, 34, 929-938. [CrossRef] [PubMed]

18. Brukner, P.; Khan, K. Brukner E Khan's Clinical Sports Medicine, 4th ed.; McGraw-Hill: Sydney, Australia, 2012.

19. Sherrard, J.; Lenne, M.; Cassell, E.; Stokes, M.; Ozanne, S.J. Strategic Direction and Advice for Increasing Safe Participation in Physical Activity in the Australian Defence Force: A Report for the Defence Health Service; Monash University Accident Research Centre: Clayton, Australia, 2002.

20. Ross, J. A review of lower limb overuse injuries during basic military training. Part 1: Types of overuse injuries. Mil. Med. 1993, 158, 410-415. [CrossRef] [PubMed]

21. Defence, D.O. Incident Capture; Australian Government Department of Defence: Canberra, Australia, 2011.

22. Pope, R.; Orr, R. Incidence rates for work health and safety incidents and injuries in Australian Army Reserve vs full time soldiers, and a comparison of reporting systems. J. Mil. Veterans Health 2017, 25, 16-25.

23. Department of Veterans' Affairs. Australian Defence Force Sports Council. Available online: http://clik.dva.gov.au/military-compensation-srca-manuals-and-resources-library/liability-handbook/ch18-sport-and-fitness-activities/181-adf-and-civilian-sport/1812-australian-defence-force-sports-council (accessed on 2 April 2016).

24. McDonald, D.; Orr, R.M.; Pope, R. A Comparison of Work Health and Safety Incidents and Injuries in Part-time and Full-time Australian Army Personnel. J. Athl. Train. 2016, 51, 880-886. [CrossRef]

25. Australian Safety and Compensation Council. Type of Occurrence Classification System; Australian Safety and Compensation Council: Canberra, Australia, 2008.

26. Jennings, B.M.; Yoder, L.H.; Heiner, S.L.; Loan, L.A.; Bingham, M.O. Soldiers with Musculoskeletal Injuries. J. Nurs. Scholarsh. 2008, 40, 268-274. [CrossRef]

27. Kreisfeld, R.; Harrison, J.E.; Pointer, S. Australian Sports Injury Hospitalisations 2011-12; Australian Institute of Health and Welfare: Canberra, Australia, 2014.

28. Hoch, M.C.; McKeon, P.O. The effectiveness of mobilization with movement at improving dorsiflexion after ankle sprain. J. Sport Rehabil. 2010, 19, 226-232. [CrossRef]

29. Carter, D.; Amblum-Almer, J. Analgesia for people with acute ankle sprain. Emerg. Nurse 2015, $23,24-31$. [CrossRef]

30. Richie, D.H.; Izadi, F.E. Return to play after an ankle sprain: Guidelines for the podiatric physician. Clin. Podiatr. Med. Surg. 2015, 32, 195-215. [CrossRef]

31. Bell, N.S.; Amoroso, P.J.; Yore, M.M.; Smith, G.S.; Jones, B.H. Self-reported risk-taking behaviors and hospitalization for motor vehicle injury among active duty Army personnel. Am. J. Prev. Med. 2000, 18, 85-95. [CrossRef]

32. Kuikka, P.I.; Pihlajamäki, H.K.; Mattila, V.M. Knee injuries related to sports in young adult males during military service-Incidence and risk factors. Scand. J. Med. Sci. Sports 2013, 23, 281-287. [CrossRef] [PubMed]

33. Palmieri-Smith, R.M.; Thomas, A. A Neuromuscular Mechanism of Posttraumatic Osteoarthritis Associated with ACL Injury. Exerc. Sport Sci. Rev. 2009, 37, 147-153. [CrossRef] [PubMed]

34. Showery, J.E.; Kusnezov, N.A.; Dunn, J.C.; Bader, J.O.; Belmont, P.J.; Waterman, B.R. The Rising Incidence of Degenerative and Posttraumatic Osteoarthritis of the Knee in the United States Military. J. Arthroplast. 2016, 31, 2108-2114. [CrossRef] [PubMed] 
35. Maupin, D.; Schram, B.; Orr, R. Tracking Training Load and Its Implementation in Tactical Populations: A Narrative Review. Strength Cond. J. 2019, 41, 1-11. [CrossRef]

36. Orr, R.; Knapik, J.J.; Pope, R. Avoiding Program-Induced Cumulative Overload (PICO). J. Spec. Oper. Med. 2016, 16, 91-95. [PubMed]

37. Hill, O.T.; Bulathsinhala, L.; Scofield, D.E.; Haley, T.F.; Bernasek, T.L. Risk factors for soft tissue knee injuries in active duty U.S. Army soldiers, 2000-2005. Mil. Med. 2013, 178, 676. [CrossRef] [PubMed]

38. Kardouni, J.R.; McKinnon, C.J.; Seitz, A.L. Incidence of shoulder dislocations and the rate of recurrent instability in soldiers. Med. Sci. Sports Exerc. 2016, 48, 2150-2156. [CrossRef]

39. Waterman, B.; Owens, B.D.; Tokish, J.M. Anterior Shoulder Instability in the Military Athlete. Sports Health 2016, 8, 514-519. [CrossRef]

40. Rahnama, N. Prevention of Football Injuries. Int. J. Prev. Med. 2011, 2, 38-40.

41. Monash University Accident Research Centre. Preventing Soccer Injuries. In Sports Medicine Australia (Victorian Branch); Sports Medicine Australia: Melbourne, Australia, 2007.

42. Loringer, K.; Bedno, S.A.; Kao, T.C.; Hauret, K. Incidence of Sports Injuries in the Military: 2008 Survey of Active Duty Military Members. Med. Sci. Sports Exerc. 2011, 43, 367. [CrossRef]

43. Heidt Jr, R.S.; Carlonas, R.L.; Traub, J.A.; Sweeterman, L.M.; Tekulve, F.X. Avoidance of soccer injuries with preseason conditioning. Am. J. Sports Med. 2000, 28, 659-662. [CrossRef] [PubMed]

44. Handoll, H.H.G.; Rowe, B.H.; Quinn, K.M.; Bie, R. Interventions for preventing ankle ligament injuries. Cochrane Libr. 2005. [CrossRef]

45. McGuine, T.A.; Keene, J.S. The effect of a balance training program on the risk of ankle sprains in high school athletes. Am. J. Sports Med. 2006, 34, 1103-1111. [CrossRef] [PubMed]

(C) 2020 by the authors. Licensee MDPI, Basel, Switzerland. This article is an open access article distributed under the terms and conditions of the Creative Commons Attribution (CC BY) license (http://creativecommons.org/licenses/by/4.0/). 